\title{
Nerve Growth Factor Rapidly Increases Muscarinic Tone in Mouse Medial Septum/Diagonal Band of Broca
}

\author{
Chia-wen K. Wu and Hermes H. Yeh \\ Center for Aging and Developmental Biology, Department of Pharmacology and Physiology, University of Rochester Medical Center, Rochester, New York \\ 14642
}

\begin{abstract}
Nerve growth factor (NGF) has been implicated in maintaining and regulating normal functioning of the septohippocampal pathway. However, many aspects of its physiological actions and the underlying mechanisms await elucidation. In this study, we investigated the effect of acute NGF exposure on neurons in the mouse medial septum/diagonal band of Broca (MS/DB), focusing on the cholinergic neurons and the subpopulation of noncholinergic neurons that were identified to be putatively GABAergic. We report that MS/DB neurons in a thin slice preparation, when exposed to NGF via bath perfusion, rapidly and indiscriminately increased the rate of spontaneous firing in all MS/DB neurons. However, focal application of NGF to individual MS/DB neurons increased spontaneous firing in cholinergic, but not in the noncholinergic, subpopulation. The NGF-induced effect on cholinergic neurons was direct, requiring activation and signaling via TrkA receptors, which were immunohistochemically localized to the cholinergic neurons in the MS/DB. TrkA receptors were absent in putative GABAergic MS/DB neurons, and blockade of TrkA signaling in these and other noncholinergic neurons had no effect on their firing activity after exposure to NGF. Conversely, methyl scopolamine, blocked the increased firing activity of noncholinergic neurons during bath perfusion of NGF. We propose a cell type-specific mode of action for NGF in the MS/DB. The neurotrophin directly enhances cholinergic neuronal activity in the MS/DB through TrkA-mediated signaling, increasing acetylcholine release and, thus, muscarinic tone. This increase in muscarinic tone, in turn, results in heightened firing activity in noncholinergic MS/DB neurons.
\end{abstract}

Key words: septohippocampal system; acetylcholine; spontaneous firing rate; nerve growth factor; TrkA receptor; p75 receptor

\section{Introduction}

The septohippocampal system has been implicated in learning and memory (Olton et al., 1978; Poucet and Herrmann, 1990; Dutar et al., 1995). Within this system, the cholinergic and GABAergic components have been subject to considerable experimental attention, having been demonstrated in previous studies to contribute prominently to learning and mnemonic functions (Deutsch and Rocklin, 1967; Chrobak and Napier, 1992; BergerSweeney et al., 2001).

Degeneration of cholinergic neurons in the human basal forebrain, the rodent homolog of the basal forebrain complex, including the medial septum/diagonal band of Broca (MS/DB), is associated with impairment of cognitive function (Whitehouse et al., 1982). Whether there is concomitant degeneration of noncholinergic MS/DB neurons, including the subpopulation of GABAergic neurons, has not been established. However, the contribution of GABAergic MS/DB neurons to the generation of

Received Dec. 6, 2004; revised Feb. 22, 2005; accepted March 16, 2005.

This work was supported by United States Public Health Service National Institutes of Health Grants R01 NS048603 and R01 AA014698. We thank Dr. Lou Hersh (University of Kentucky, Lexington, KY) for the ChAT antibody, Dr. Roman Giger (University of Rochester, Rochester, NY) for the $75^{\mathrm{NTR}-1-}$ mouse line, and members of the Yeh laboratory for helpful discussion and technical consult.

Correspondence should be addressed to Dr. Hermes H. Yeh, Box 645, Center for Aging and Developmental Biology, University of Rochester Medical Center, 601 Elmwood Avenue, Rochester, NY 14642. E-mail: hermes_yeh@urmc.rochester.edu.

DOI:10.1523/JNEUROSCI.4957-04.2005

Copyright $@ 2005$ Society for Neuroscience $\quad 0270-6474 / 05 / 254232-11 \$ 15.00 / 0$ slow rhythmic theta activity (Green and Arduini, 1954; Vanderwolf, 1969; Winson, 1974; Cobb et al., 1995; Tøth et al., 1997) is consistent with them playing a role in the maintenance of cognition (Green and Arduini, 1954; Vanderwolf, 1969; Winson, 1974).

With regard to the cholinergic system in the MS/DB, it has been proposed that intraseptal release of acetylcholine results in an ambient accumulation of the neurotransmitter that maintains a muscarinic tone in the MS/DB (Alreja et al., 2000; Wu et al., 2000). Immunocytochemical studies revealed at the ultrastructural level cholinergic innervation of GABAergic neurons in the MS/DB (Bialowas and Frotscher, 1987; Onteniente et al., 1987; Leranth and Frotscher, 1989; Brauer et al., 1998), demonstrating the presence of an intraseptal network of cholinergic collaterals and providing the neuroanatomical substrate for a muscarinic tone in the MS/DB. In this study, we demonstrate that nerve growth factor (NGF) applied directly into the MS/DB rapidly increases muscarinic tone, as reflected by an elevated firing of noncholinergic neurons.

Indeed, NGF has been shown to play an essential role in promoting the survival of MS/DB neurons and in regulating the activity of cholinergic neurons (Hefti, 1986; Mobley et al., 1986; Williams et al., 1986; Wilcox et al., 1995; Backman et al., 1996; Lucidi-Phillipi et al., 1996; Gibbs and Martynowski, 1997; Gustilo et al., 1999; Ha et al., 1999). The source of NGF is generally believed to be extraseptal, notably the hippocampus. [ $\left.\mathrm{I}^{125}\right]$ - 
labeled NGF in the hippocampus can be internalized via TrkA receptors and retrogradely transported to the cell bodies of neurons in the MS/DB (Seiler and Schwab, 1984; DiStefano et al., 1992; Lapchak et al., 1993). Other investigations reveal NGF mRNA expression in hippocampal neurons projecting to the MS/ $\mathrm{DB}$, indicating an additional anterograde mode of transport (Lauterborn et al., 1993; Tøth et al., 1993; Rocamora et al., 1996; Acsády et al., 2000). Regardless of the mode of transport, these studies suggest that neurons in the MS/DB have direct access to NGF released into its extracellular milieu. We report here that NGF rapidly increases the rate of spontaneous firing in cholinergic and noncholinergic subpopulations of MS/DB neurons through distinctly different mechanisms.

\section{Materials and Methods}

Preparation of brain slices. Postnatal day 11-14 wild-type C57BL/6 mice were decapitated, and the brains were quickly removed and immersed in oxygenated ice-cold cutting solution containing the following (in $\mathrm{mm}$ ): 110 sucrose, $3 \mathrm{KCl}, 7 \mathrm{MgCl}_{2}, 1.25 \mathrm{NaH}_{2} \mathrm{PO}_{3}, 0.5 \mathrm{CaCl}_{2}, 28 \mathrm{NaHCO}_{3}, 5$ dextrose, 0.6 ascorbate, and 0.1 kynurenate. Thin $(200 \mu \mathrm{m})$ coronal brain slices containing MS/DB were obtained using a vibroslicer (World Precision Instruments, Sarasota, FL). Slices were incubated at room temperature in artificial CSF (aCSF) for at least 60 min before being used for recording. The aCSF contained the following (in $\mathrm{mM}$ ): $125 \mathrm{NaCl}, 2.5 \mathrm{KCl}$, 2.0 $\mathrm{CaCl}_{2}, 1.0 \mathrm{MgCl}_{2}, 1.25 \mathrm{NaH}_{2} \mathrm{PO}_{3}, 26 \mathrm{NaHCO}_{3}$, and 10 glucose. The slices were then placed in a custom-made recording chamber, stabilized by an overlaying platinum ring strung by a plastic mesh, and perfused continuously with aCSF at a rate of $1 \mathrm{ml} / \mathrm{min}$. All solutions used for cutting, incubating, and perfusing the slices were bubbled with $5 \% \mathrm{CO}_{2} /$ $95 \% \mathrm{O}_{2}$. Slices were viewed under Hoffman Modulation Contrast optics using a $40 \times$ extra-long working-distance water-immersion objective (Olympus Optical, Melville, NY). One set of experiments used p75 ${ }^{\mathrm{NTR}-1-}$ mice (Lee et al., 1992).

During postnatal development in rat, the septohippocampal system acquires the adult pattern at approximately postnatal day 14 (Milner et al., 1983; Linke and Frotscher, 1993; Linke et al., 1995; Bender et al., 1996). Although similar information is limited for mouse (Ward and Hagg, 1999, 2000; Clancy et al., 2001), it has been reported that the developmental schedule of the mouse CNS precedes that of the rat by $\sim 2$ d. According to this timetable, the slices used for experiments in this study were derived from mice when the septohippocampal system is in a relatively mature state.

Whole-cell patch-clamp recording. Patch-clamp recording electrodes were pulled from filament-filled borosilicate glass capillary tubes (Sutter Instruments, Novato, CA). The electrodes had resistances between 8 and $10 \mathrm{M} \Omega$ when filled with internal solution containing the following (in $\mathrm{mm}$ ): $140 \mathrm{KCl}, 1.8 \mathrm{CaCl}_{2}, 1.0 \mathrm{MgCl}_{2}$, and 5.0 HEPES. $\mathrm{Mg}^{2+}$-ATP (3 mM) and leupeptin $(0.1 \mathrm{~mm})$ were added to prevent possible rundown and proteolysis. Lucifer yellow (0.5\%; Molecular Probes, Eugene, OR) was routinely included to facilitate on-line visualization and post hoc identification of the recorded cells. Recordings were performed on a heated stage using an EPC-7 amplifier (HEKA Elektronik, Lambrecht, Germany) at $32^{\circ} \mathrm{C}$. Cells were first voltage clamped at $-70 \mathrm{mV}$ and then switched to the current-clamp mode to monitor action potentials, filtered at $10 \mathrm{kHz}$, digitized using Clampex version 8.0 (Axon Instruments, Foster City, CA), and analyzed using Mini Analysis software (version 5.1; Synaptosoft, Decatur, GA).

Application of drugs. In experiments involving focal delivery of drugs in the immediate vicinity of the cell under study, the drugs were loaded into separate barrels of a custom-made six-barrel drug pipette assembly, which was made using filament-filled borosilicate glass capillary tubes (Sutter Instruments) that were fused by twisting under heat and pulled to a fine point. One of the barrels was routinely filled with aCSF to control for mechanical artifacts attributable to bulk flow and to clear drugs between applications. The drug pipette was mounted onto a micromanipulator and navigated under visual control to be within $10 \mu \mathrm{m}$ of the soma of the septal neuron under study. Drug solutions were delivered by reg-
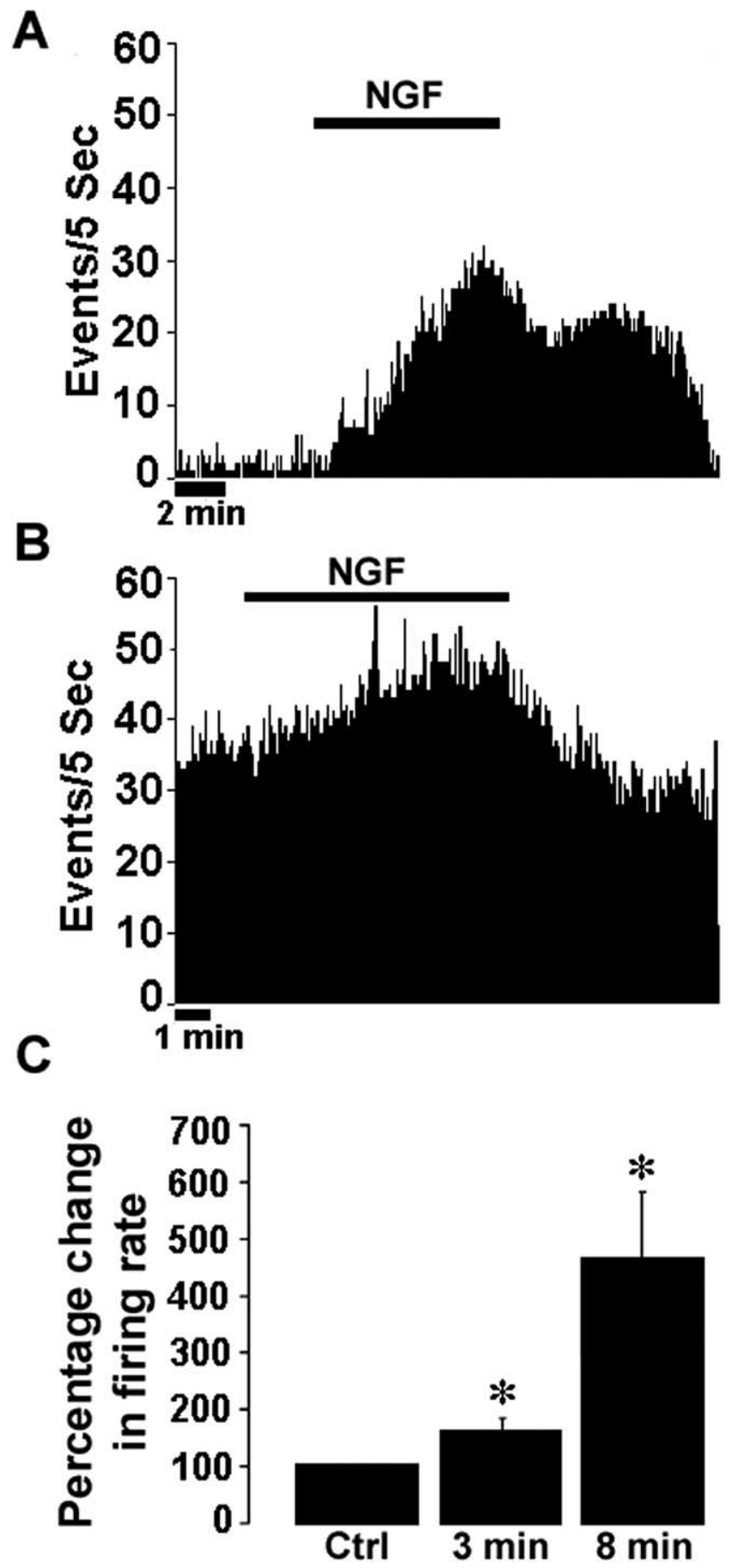

Figure 1. Bath perfusion of NGF increases firing in MS/DB neurons. $A, B$, Representative rate-meter records of two MS/DB neurons displaying a slow $(\boldsymbol{A})$ and fast $(\boldsymbol{B})$ rate of spontaneous firing before [control (Ctrl)], during, and after bath perfusion of NGF (100 ng/ml) perfusion. C, Normalized histogram summarizing mean firing rate of all of the recorded neurons. The spontaneous firing rate was significantly faster when assessed at 3 and $8 \mathrm{~min}$ after NGF perfusion $\left({ }^{*} p<0.05\right.$; Student's $t$ test).

ulated pulses of pressure ( $\leq 3$ psi, Picospritzer; General Valve Company, Fairfield, NJ). In experiments involving bath perfusion of drugs, the slices were first perfused continuously with aCSF and then switched to aCSF containing the drugs at the desired concentration. Using our system of perfusion, the drug-containing aCSF equilibrates in $\sim 3$ min during switching. All drugs were diluted from stock with aCSF immediately before each recording session to the desired concentrations. NGF (2.5S) was purchased from Harlan (Madison, WI). All other chemicals were purchased from Sigma (St. Louis, MO). 
Immunohistochemistry. After electrophysiological recording, brain slices were fixed with $4 \%$ paraformaldehyde in PBS overnight and permeabilized in PBS containing 0.5\% Triton X-100 (PBS/TX). All subsequent reactions were performed in the PBS/TX. The slices were incubated in $10 \%$ normal goat serum for $1 \mathrm{~h}$, followed by incubation for $48 \mathrm{~h}$ in one of the following: (1) rabbit anti-choline acetyltransferase (ChAT) (1:1000); (2) a mixture of rabbit anticalretinin (1:1000, Chemicon, Temecula, CA), mouse anti- parvalbumin, and mouse anticalbindin (both at 1:1000; Sigma); or (3) rabbit anti-TrkA receptor (1:100; Upstate Biotechnology, Charlottesville, VA). The slices were subsequently incubated at $4^{\circ} \mathrm{C}$ for $24 \mathrm{~h}$ in the appropriate Alexa Fluor 568- or 594-conjugated secondary antibody (1:800; Molecular Probes).

To assess colocalization of TrkA and GABAergic markers, whole mouse brains were immersed fixed with $4 \%$ paraformaldehyde in PBS, and $25 \mu \mathrm{m}$ frozen sections containing the MS/DB were processed immunohistochemically. The sections were permeabilized in PBS/TX for 30 min, incubated in PBS containing $10 \%$ normal goat serum for another $30 \mathrm{~min}$, and then incubated at $4^{\circ} \mathrm{C}$ for $24 \mathrm{~h}$ with a mixture of mouse anti-parvalbumin, mouse anticalbindin, and rabbit anti-TrkA receptor. The sections were subsequently incubated at room temperature for $2 \mathrm{~h}$ with Alexa Fluor 488 goat anti-mouse IgG and Alexa Fluor 568 goat antirabbit IgG (both at 1:500). Fluorescent images were captured using the Olympus Optical FV300 laser-scanning confocal microscope system.

Western blot analysis. Protein extract was first incubated with wheat germ agarose beads (Accurate Chemicals, Westbury, NY) at $4^{\circ} \mathrm{C}$ for $1 \mathrm{~h}$ to remove unglycosylated protein. The beads were washed three times with radioimmunoprecipitation assay buffer, resuspended in $1 \times$ reducing sample loading buffer, and boiled for 10 min before being loaded on a $7.5 \%$ SDSpolyacrylamide gel. The gels were transferred to nitrocellulose membranes (Bio-Rad, Hercules, CA), washed with TBS-T $(0.05 \%$ of Tween in TBS), and blocked using 5\% nonfat milk in TBS-T for $2 \mathrm{~h}$ in room temperature. The mem-

branes were then incubated overnight at $4^{\circ} \mathrm{C}$ with the mouse antiphosphorylated TrkA (at tyrosine residue 490) antibody (1:1000; Sigma), washed three times with $5 \%$ nonfat milk in TBS-T, incubated with horseradish peroxidase-conjugated goat anti-mouse antibody (1:5000; Chemicon) at room temperature for $2 \mathrm{~h}$, and visualized using enhanced chemiluminescence substrate (Chemicon).

\section{Results \\ Bath perfusion of NGF increases firing of cholinergic and noncholinergic MS/DB neurons}

We first asked whether NGF exerted a short-term and rapid effect on the firing activity of MS/DB neurons. NGF was included in the aCSF used to perfuse slices, thus exposing the entire preparation to the neurotrophin, and the firing rate of MS/DB neurons was compared before, during, and after exposure to NGF. Individual neurons in the MS/DB display different rates of firing (Markram and Segal, 1990; Jones et al., 1999; Sotty et al., 2003), and Figure 1, $A$ and $B$, illustrates rate-meter records obtained from a slowfiring $(0.5 \mathrm{~Hz})$ and fast-firing $(7.2 \mathrm{~Hz})$ neuron, respectively.
A2

B1 B2
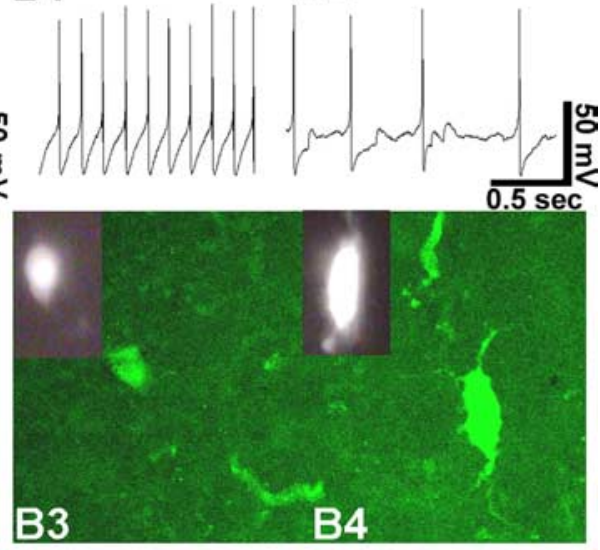

$0.5 \mathrm{sec}<$
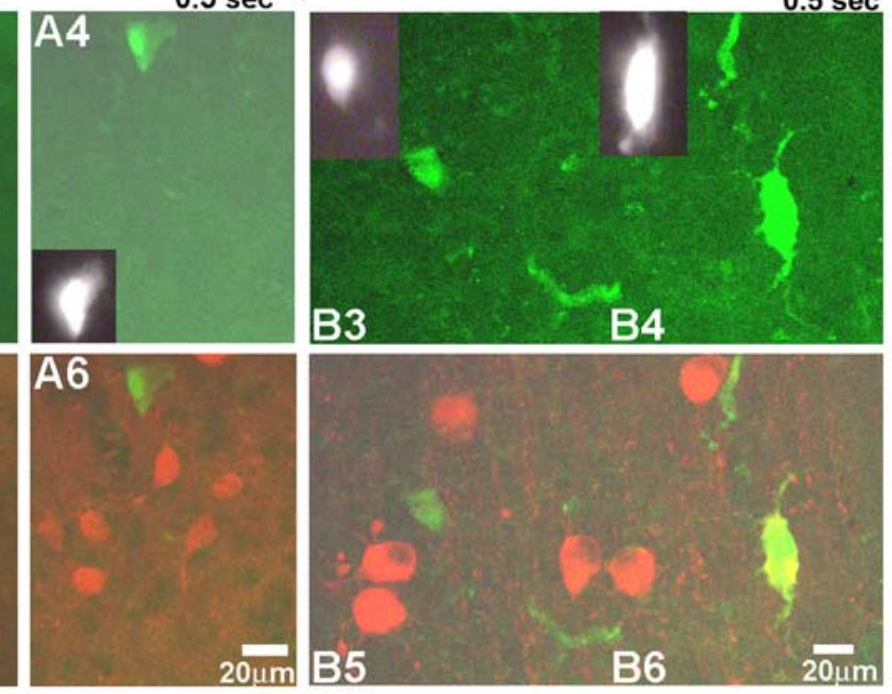

C2

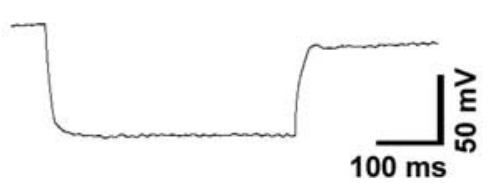

Figure 2. Fast-firing neurons are immunopositive for GABAergic markers, and slow-firing neurons are immunopositive for bumin/calbindin/calretinin antibodies. Overlay images show immunolabeling in the fast-firing cell ( $A$ 5) but not in the slow-firing .B1, B2, Representative traces of spontaneous firing corresponding to a fast-firing and a slow-firing cell, respectively. The recording ( $\boldsymbol{B} 3$, inset), is located on the left, and the slow-firing cell ( $\boldsymbol{B} 4$, inset) is located on the right. Both neurons were recovered a noncholinergic and a cholinergic neuron, respectively, to a hyperpolarizing current step. Note the depolarization sag in the noncholinergic neuron. Calibration applies to both $\mathbf{C}$ and $\mathbf{C}$.

Within 3 min of exposing the slice to aCSF containing NGF (100 $\mathrm{ng} / \mathrm{ml}$ ), the firing activity began to increase in both neurons.

Figure $1 C$ summarizes the percentage change in mean firing rate of MS/DB neurons 3 and $8 \mathrm{~min}$ after bath perfusion of NGF. The mean rate of spontaneous firing increased $60 \pm 25 \%$ by 3 min and $365 \pm 119 \%$ (mean \pm SEM; $p<0.05$; Student's $t$ test; $n=15$ ) by $8 \mathrm{~min}$ relative to that monitored during the control (pre-NGF exposure) period. The effect of NGF appeared to be time dependent, insofar as an 8 min exposure resulted in a more pronounced increase in mean firing rate than that observed at 3 $\min (p<0.05$; Student's $t$ test).

We then asked if the observed acute effect of NGF on firing rate could be attributed to the cholinergic and the GABAergic subpopulations, two prominent cell types in the MS/DB (Panula et al., 1984; Freund and Antal, 1988; Freund, 1989; Kiss et al., 1990; Palacios et al., 1991; Sotty et al., 2003). Individual MS/DB neurons, identified by filling with Lucifer yellow during wholecell recording, were recovered after fixation, and the slices were processed immunohistochemically with either a mixture of anti- 


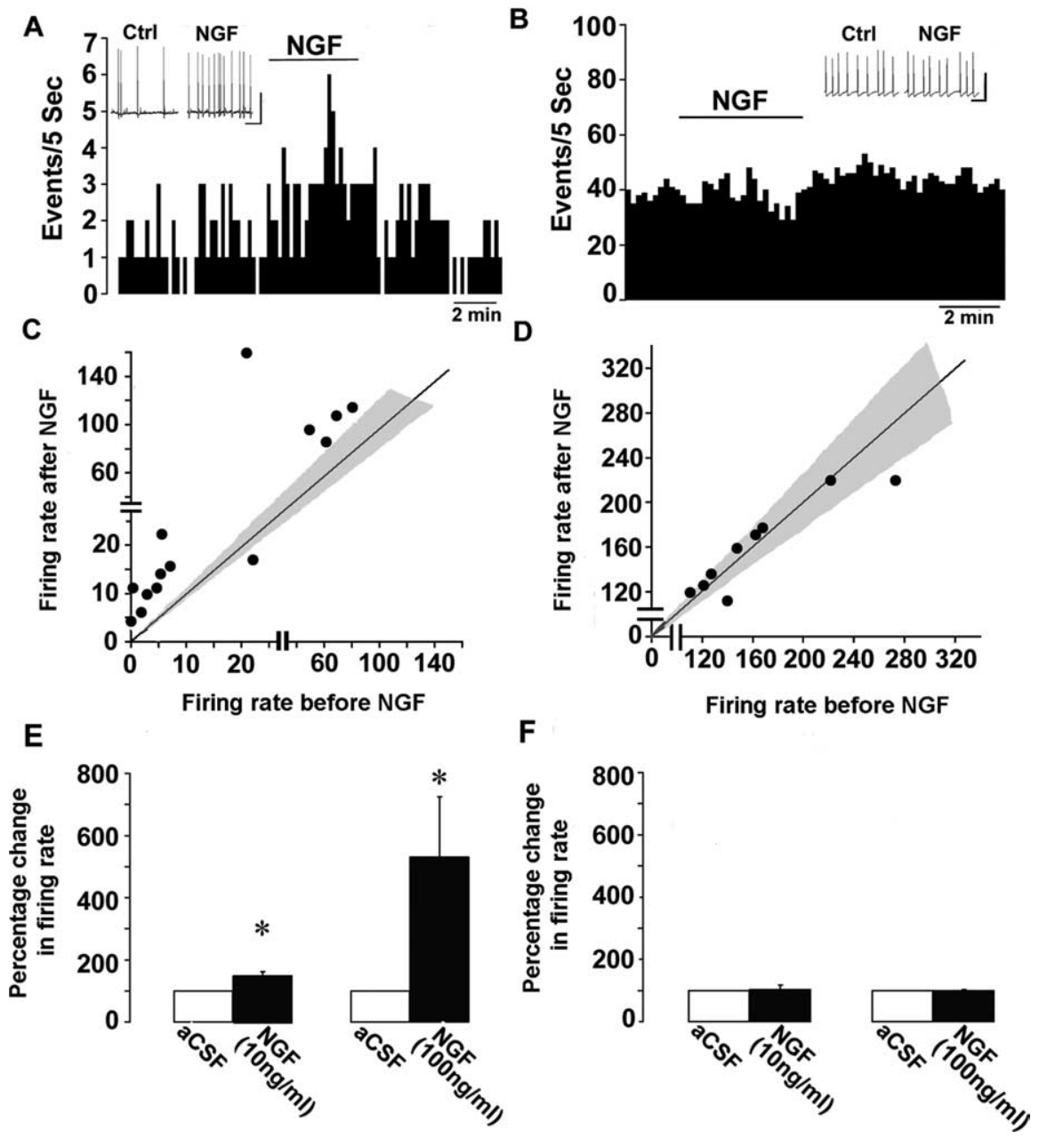

Figure 3. Focal application of NGF acutely increases firing in cholinergic, but not noncholinergic, neurons. $\boldsymbol{A}, \boldsymbol{B}$, Representative rate-meter records of slow-firing and fast-firing neurons, respectively, illustrate spontaneous firing before, during, and after NGF $(100 \mathrm{ng} / \mathrm{ml})$ application. Insets show digitized traces from the same cells. Calibration: $0.5 \mathrm{~s}(\boldsymbol{A})$ and $1 \mathrm{~s}(\boldsymbol{B}), 50 \mathrm{mV}$. Ctrl, Control. $\boldsymbol{C}$, $D$, Summary graph of the effect of NGF on cholinergic and noncholinergic neurons, respectively. Each symbol represents data obtained from one neuron. The $45^{\circ}$ equivalence line represents the result expected if the firing rate remains unchanged after application of NGF. The shaded area represents a $10 \%$ increase or decrease and reflects the range of variability normally encountered while monitoring the rate of spontaneous firing in MS/DB neurons. Most of the slow-firing neurons show increased firing rates, whereas fast-firing neurons showed more variable responses. $\boldsymbol{E}, \boldsymbol{F}$, Normalized histograms summarizing mean firing rates of cholinergic $(n=15)$ and noncholinergic $(n=11)$ neurons in the presence of 10 or $100 \mathrm{ng} / \mathrm{ml}$ NGF. During acute and focal NGF exposure, the mean rate of spontaneous firing in cholinergic neurons was significantly faster in both concentrations $(p<0.05$; Student's $t$ test) than that during the control (pre-NGF exposure) period, whereas that of noncholinergic neurons was unaffected ( $p>0.05$; Student's $t$ test). Asterisks in $\boldsymbol{E}$ denote statistical significance.

bodies against calcium binding proteins typically expressed by GABAergic cells, notably parvalbumin, calbindin, and calretinin (Freund and Antal, 1988; Freund, 1989; Celio, 1990; Kiss et al., 1990; Van der Zee and Luiten, 1994), or an antibody against ChAT, a marker for cholinergic neurons (Fig. 2). The mixture of antibodies for calcium binding proteins was used to optimize labeling of putative GABAergic MS/DB neurons, because antibodies against GAD or GABA did not effectively reveal neuronal profiles in the MS/DB slices without previous treatment with colchicine.

Parvalbumin/calbindin/calretinin-immunoreactive MS/DB neurons fired spontaneously at a mean rate of $7.0 \pm 1.0 \mathrm{~Hz}$ (range, $4.0-22.8 \mathrm{~Hz} ; n=18$ ), significantly different from that of ChAT-immunoreactive neurons $(1.5 \pm 0.3 \mathrm{~Hz}$; range, $0-3.9 \mathrm{~Hz}$; $n=16 ; p<0.001$; Student's $t$ test). In Figure 2A5, the antibody mixture of GABAergic markers revealed numerous immunopo- sitive neurons, including the Lucifer yellow-filled cell whose rate of spontaneous firing [22.8 Hz (Fig. 2A1)] was classified as being fast $(\geq 4.0 \mathrm{~Hz})$. Such a correlation between a fast rate of spontaneous firing and immunoreactivity to parvalbu$\mathrm{min} /$ calbindin/calretinin was found in 12 of 13 neurons. Parvalbumin/calbindin/ calretinin immunoreactivity was absent in four of five MS/DB neurons displaying slow rates of firing $[\leq 3.0 \mathrm{~Hz}$ (Fig. 2A6)]. In contrast, a reciprocal correlation was revealed between firing rate of $\mathrm{MS} / \mathrm{DB}$ neurons and ChAT immunoreactivity. Fast-firing cells, such as the one illustrated in Figure $2 \mathrm{~B} 3$ [5.5 Hz (Fig. 2 B1) ], were not immunopositive for ChAT. In the same slice, a slow-firing neuron nearby was immunopositive for ChAT (Fig. 2B4,B6). Hyperpolarizing current steps elicited a depolarizing sag in the majority (93\%) of the putative GABAergic, but not cholinergic (38\%), MS/DB neurons (Fig. $2 C 1, C 2)$. These results are consistent with previous findings in rat MS/DB (Griffith and Matthews, 1986; Markram and Segal, 1990; Jones et al., 1999; Alreja et al., 2000; Wu et al., 2000; Sotty et al., 2003). Thus, slow-firing MS/DB neurons are heretofore operationally referred to as cholinergic neurons. The fast-firing MS/DB neurons are referred to as "noncholinergic neurons." In specific cases in which individual fast-firing neurons were identified immunohistochemically to express parvalbumin, calbindin, and/or calretinin, they are referred to as GABAergic MS/DB neurons, with the caveat that this classification does not take into account the molecular diversity of other fast-firing cell types resident in the MS/DB that have been reported to coexpress mRNAs encoding ChAT and GAD, such as the glutamatergic neurons (Sotty et al., 2003), or to coexpress calcium-binding protein transcripts (Han et al., 2002). Given this, the results of these experiments indicate that bath application of NGF generally increased firing of MS/DB neurons.

Focal application of NGF selectively increases spontaneous firing in cholinergic MS/DB neurons

Bath perfusion of NGF served to demonstrate the elemental phenomenon that the neurotrophin increased firing activity in MS/DB neurons but did not afford the resolution necessary to examine the mechanism underlying the NGF-induced effect on individual neurons classified as being cholinergic and noncholinergic neurons. To this end, NGF (10 or $100 \mathrm{ng} / \mathrm{ml}$ ) was delivered focally and directly onto the neuron under study using a multibarrel drug pipette assembly, and the rate of spontaneous firing of MS/DB neurons was compared before, during, and after a 3 min application of NGF.

Figure 3, $A$ and $B$, illustrates rate-meter records taken from a cholinergic and a noncholinergic neuron, respectively. The insets 
show representative traces from the corresponding neurons recorded before (control) and during NGF (100 ng/ml) application. In the cholinergic neuron (Fig. $3 A$ ), exposure to NGF promptly increased (within $1 \mathrm{~min}$ ) the rate of spontaneous firing. Figure $3 C$ summarizes, in the form of a scatter plot, data obtained from 16 cholinergic neurons. Each point denotes the change in the rate of spontaneous firing during NGF exposure obtained from one neuron. The $45^{\circ}$ equivalence line represents the result expected if the firing rate remained unchanged during exposure to NGF. The shaded area represents a $10 \%$ increase or decrease and reflects the range of variability normally encountered while monitoring the rate of spontaneous firing in MS/DB neurons. The great majority of the points (15 of 16) were positioned above the $45^{\circ}$ equivalence line and the shaded area, indicating that focal application of NGF consistently increased the rate of spontaneous firing in cholinergic MS/DB neurons. Conversely, in the noncholinergic neuron (Fig. 3B), focal application of NGF did not alter the rate of spontaneous firing. The scatter plot in Figure 3D, representing a sampling of 11 noncholinergic MS/DB neurons, revealed that the majority of the points (9 of 11) were situated adjacent to the $45^{\circ}$ equivalence line and within the shaded area, indicating little or no change in the firing rate with exposure to NGF. In the remaining two noncholinergic neurons, focal application of NGF resulted in a decrease in spontaneous firing that did not reach statistical significance.

Two concentrations of NGF ( 10 and $100 \mathrm{ng} / \mathrm{ml}$ ) were used to assess the rapid effect of the neurotrophin on the firing rate of cholinergic neurons (Fig. 3E). The mean rate of spontaneous firing increased $47 \pm 14 \%$ with $10 \mathrm{ng} / \mathrm{ml} \mathrm{NGF}$ (mean \pm SEM; $p<$ 0.05 ; Student's $t$ test; $n=7$ ) and $431 \pm 193 \%$ with $100 \mathrm{ng} / \mathrm{ml} \mathrm{NGF}$ (mean \pm SEM; $p<0.05$; Student's $t$ test' $n=15$ ) relative to that recorded during the control period. The firing rate of noncholinergic neurons was not significantly altered (Fig. $3 F$ ) with either 10 ng/ml NGF (3 cases) or $100 \mathrm{ng} / \mathrm{ml}$ (11 cases).

\section{TrkA signaling mediates the rapid effect of NGF on cholinergic MS/DB neurons}

Our results thus far indicated that both bath perfusion and focal application of NGF increased the rate of spontaneous firing in cholinergic MS/DB neurons, whereas an increase in the firing of noncholinergic neurons was dependent on the mode of NGF exposure. Based on these findings, we tested the hypothesis that different mechanisms may underlie the rapid effect of NGF on cholinergic and noncholinergic neurons. First, double-label immunohistochemistry was performed on $25 \mu \mathrm{m}$ histological sections using antibodies against the combination of parvalbumin and calbindin as markers of putative GABAergic neurons and the receptor tyrosine kinase TrkA (Fig. $4 A, B$ ). In this specific set of experiments, the rabbit antibody against calretinin was excluded because it was incompatible with colabeling using the rabbit antibody against TrkA. Overlay of the images (Fig. 4C) revealed no overlap between TrkA and parvalbumin/calbindin-immunoreactive profiles, suggesting that noncholinergic MS/DB neu- rons, including those classified as being GABAergic in this study, do not express TrkA.

Second, individual MS/DB neurons assessed for the effect of focal NGF exposure were identified after fixation of the slices and examined for the expression of TrkA immunoreactivity (Fig. 5). The cholinergic neuron illustrated in Figure $5 A-D$ displayed increased firing in response to acute NGF application (Fig. 5D), consistent with the result presented previously (Fig. $3 A$ ). This cell was filled with Lucifer yellow during recording (Fig. $5 A$, inset) and reexamined after fixation and immunohistochemical processing of the slice with an antibody against TrkA. Numerous TrkA-immunoreactive profiles are present in the MS/DB, including the electrophysiologically recorded neuron (Fig. 5B,C). Thus, cholinergic MS/DB neurons express TrkA receptors. In contrast, acute NGF application did not increase firing in the Lucifer yellow-filled noncholinergic neuron illustrated in Figure $5 E-H$, and this cell did not display TrkA immunoreactivity (Fig. $5 F, G)$. These results directly correlate an acute NGF-induced increase in spontaneous firing with TrkA receptor expression in cholinergic MS/DB neurons.

Given that cholinergic MS/DB neurons express TrkA receptors, we then investigated whether TrkA signaling is required for NGF to increase spontaneous firing in these neurons. Before focal application of NGF, the cells were first exposed to K252a (200 $\mathrm{nM})$, a tyrosine kinase inhibitor, which was delivered via a separate barrel of the drug pipette assembly. Figure $6 \mathrm{~A}$ illustrates that preexposure to K252a, but not the inactive analog K252b (200 $\mathrm{nM})$, effectively blocked the acute NGF-induced increase in firing in cholinergic neurons. The same results were obtained in nine cholinergic neurons so tested (Fig. 6B). Neither preexposure of noncholinergic neurons to K252a or K252b altered significantly the rate of spontaneous firing during focal application of NGF (data not shown). Consistent with this finding, Western blots revealed stronger signals for phosphorylated TrkA receptors in MS/DB tissue microdissected from slices that had been exposed to NGF ( $p<0.05$; Student's $t$ test; $n=5$ ) (Fig. $6 C, D$ ).

To demonstrate further the requirement for TrkA signaling, 

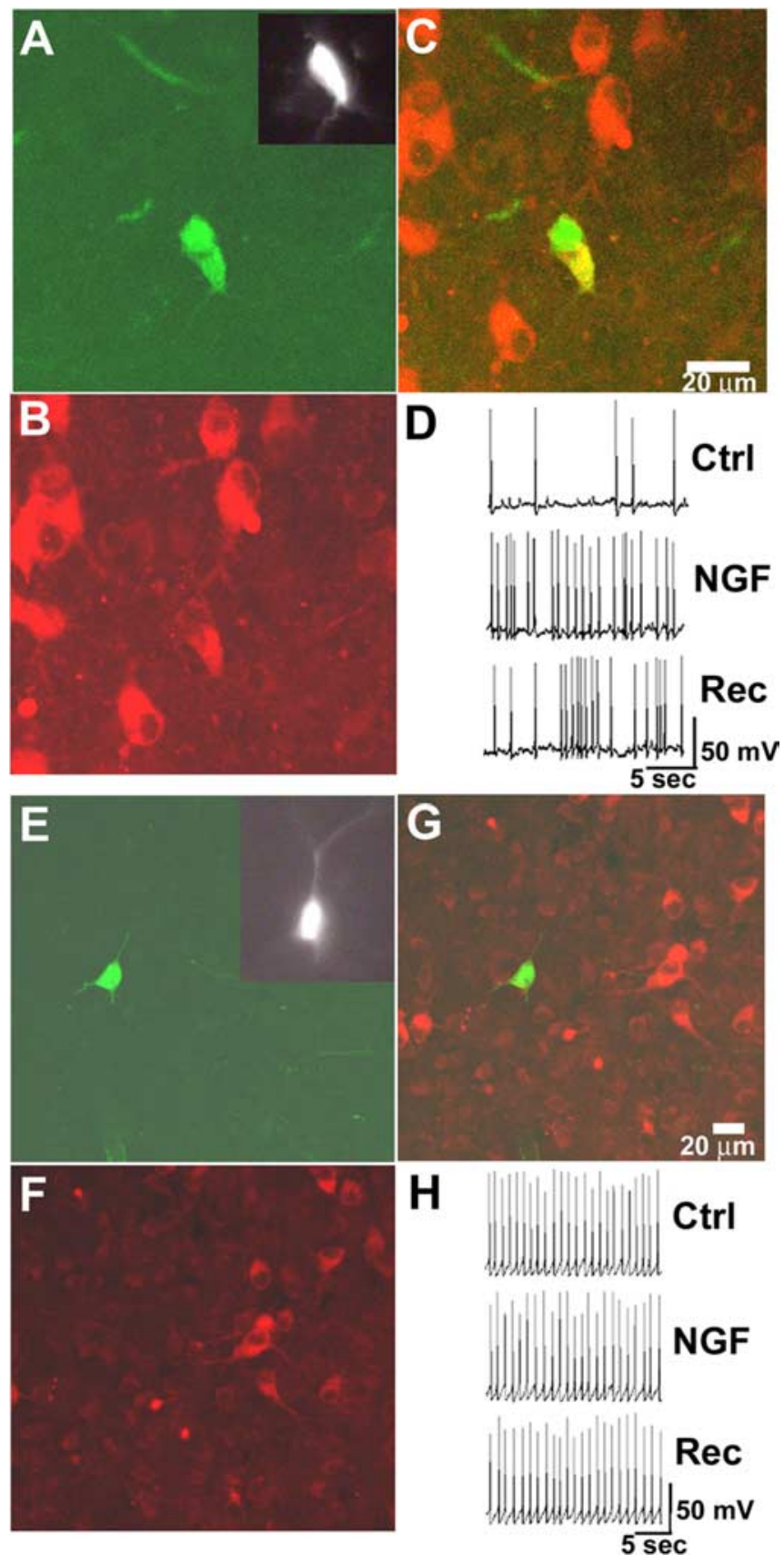

Figure 5. Cholinergic neurons, but not noncholinergic neurons, respond to acute NGF application and display TrkA immunoreactivity. $\boldsymbol{A}, \boldsymbol{E}$, Two separate cells filled with Lucifer yellow during recording (insets) and recovered after fixation of the slices. $\boldsymbol{B}, \boldsymbol{F}$, Only the cell shown in $\boldsymbol{B}$ is immunoreactive to the antibody against TrkA. $C, G, 0$ verlay images of $A, B$ and $E, F$, respectively. $\boldsymbol{D}, \boldsymbol{H}$, Representative traces of the cholinergic and noncholinergic neuron shown in $\boldsymbol{A}$ and $E$, respectively, of spontaneous firing before [control (Ctrl)], during, and after [recovery (Rec)] NGF application.

we preexposed the recorded cells to TrkA-Fc, which competes with the endogenous TrkA receptor by scavenging and sequestering NGF. Indeed, preexposure of the cholinergic neuron illustrated in Figure $7 A$ to TrkA-Fc $(1 \mu \mathrm{g} / \mathrm{ml})$ prevented the increase in the rate of spontaneous firing normally observed during focal application of NGF (100 ng/ml). Figure 7A also illustrates that an NGF-induced increase in firing can be demonstrated in the same cell after wash off of TrkA-Fc by aCSF. Data obtained from seven cholinergic neurons are summarized in Figure $7 B$. In control experiments, preexposing cholinergic neurons to TrkA-Fc that had been inactivated by boiling for $2 \mathrm{~h}$ did not suppress the NGF-induced effect (Fig. 7C), with cholinergic neurons showing an overall $129 \pm 62 \%$ (mean \pm SEM; $p<0.05$; Student's $t$ test) increase in spontaneous firing.

The p75 receptor ( $\mathrm{p} 75^{\mathrm{NTR}}$ ) is the low-affinity pan neurotrophin receptor. In the MS/DB, cholinergic, but not noncholinergic, neurons express p75 ${ }^{\text {NTR }}$ (Berger-Sweeney et al., 2001). To investigate whether $\mathrm{p} 75^{\mathrm{NTR}}$ is involved in mediating the observed acute NGF effect, we assessed spontaneous firing before, during, and after focal delivery of NGF (100 ng/ml) to MS/DB neurons in slices obtained from mice bearing an exon III mutation that leads to loss of full-length p $75^{\mathrm{NTR}}$ expression (p75 ${ }^{\mathrm{NTR}-1-}$ ) (Lee et al., 1992). In 12 cholinergic neurons tested (Fig. 8), NGF application significantly increased firing rate of cholinergic neurons by $94 \pm$ $45 \%$ (mean \pm SEM; $p<0.05$; Student's $t$ test). Thus, the acute effect of NGF persisted despite the absence of $\mathrm{p} 75^{\text {NTR }}$.

Together, the results indicate that TrkA phosphorylation and downstream signaling are required for the manifestation of the NGF-induced rapid increase in spontaneous firing in cholinergic MS/DB neurons. The absence of TrkA expression in noncholinergic neurons renders them insensitive to a direct action of NGF.

\section{Enhanced acetylcholine release mediates the rapid effect of NGF on noncholinergic MS/DB neurons}

An NGF-induced increase in the firing activity of cholinergic neurons would be expected to augment acetylcholine release and thus the ambient level of acetylcholine in the MS/DB. In rat, the presence of an ambient level of acetylcholine in the MS/DB is supported by neuroanatomical and electrophysiological evidence, and ultrastructural studies have demonstrated intraseptal cholinergic synapses on GABAergic neurons in the MS/DB (Bialowas and Frotscher, 1987; Leranth and Frotscher, 1989; Brauer et al., 1998; Alreja et al., 2000; Wu et al., 2000). In this study, to demonstrate the presence of ambient acetylcholine in mouse, the acetylcholine esterase inhibitor neostigmine was applied onto MS/DB neurons while the rate of spontaneous firing was monitored. A neostigmine-induced augmentation of the level of acetylcholine in the MS/DB would be indicated by a heightened level of firing in noncholinergic neurons. Indeed, this was the experimental outcome. The rate-meter records in the top panels in Figure 9, $A$ and $C$, were taken from a noncholinergic and cholinergic MS/DB neuron, respectively. The firing rate monitored in the noncholinergic neuron (Fig. 9A) increased within $3 \mathrm{~min}$ of a 7 min application of neostigmine $(20 \mu \mathrm{M})$. Such an increase was observed in 14 of 16 noncholinergic neurons but was not observed in the majority of cholinergic neurons tested (11 of 15). Neostigmine significantly increased firing rates in noncholinergic neurons $(54.7 \pm 18.4 \%$; mean \pm SEM; $p<0.05$; Student's $t$ test; $n=16$ ) (Fig. $9 B$ ) but not in cholinergic neurons $(18.5 \pm$ $12.1 \%$; mean \pm SEM; $p>0.05$; Student's $t$ test; $n=15$ ) (Fig. 9D). These results are consistent with neostigmine augmenting the level of ambient acetylcholine.

Methyl scopolamine, a muscarinic receptor antagonist, blocked the neostigmine-induced increase in firing of noncholinergic neurons. As shown in Figure $10 \mathrm{~A}$, an initial focal application of neostigmine increased the rate of spontaneous firing in the noncholinergic neuron. This effect was subsequently abolished by a concomitant application of methyl scopolamine (four of six noncholinergic MS/DB neurons) (Fig. 10B). Methyl scopolamine also blocked the increase in firing of noncholinergic neurons during bath perfusion of NGF (Fig. 11A). Figure 11C summarizes the mean firing rates of noncholinergic $(n=8)$ and 
cholinergic $(n=6)$ neurons after concomitant bath perfusion of NGF and methyl scopolamine. The mean rate of spontaneous firing monitored in noncholinergic neurons remained unaltered relative to that monitored during the control (preNGF/methyl scopolamine exposure) period, indicating that the NGF-induced increase in noncholinergic neurons was abolished by methyl scopolamine ( $p>$ 0.05 ; Student's $t$ test). In cholinergic neurons, of which one example is shown in Figure $11 B$, the NGF-induced effect was insensitive to blockade by methyl scopolamine, because the spontaneous firing rate increased $166 \pm 34 \%$ (mean \pm SEM; $p<$ 0.05 ; Student's $t$ test) despite the presence of the muscarinic receptor blocker. Together, the results indicate that methyl scopolamine, by blocking muscarinic receptors, prevented the increase in firing activity normally observed in noncholinergic neurons as the result of an NGF- or neostigmine-induced elevation of ambient acetylcholine in the MS/DB.

\section{Discussion}

Neurotrophins have been shown to modulate the short-term neuronal excitability and synaptic transmission (Huang and Reichardt, 2001). Whereas much experimental attention has been directed at investigating the acute effects of brain-derived neurotrophic factor (Kafitz et al., 1999; Blum et al., 2002; Cheng and Yeh, 2003, 2005), similar rapid effects of NGF have not been described. The present study demonstrates for the first time that short-term application of NGF differentially affects spontaneous firing in cholinergic and noncholinergic neurons of the mouse MS/DB. Whether delivered focally onto individual MS/DB neurons or generally to whole slices, NGF increased firing in cholinergic neurons in a manner that was abolished with pharmacological disruption of TrkA signaling. Conversely, only perfusion of whole slices with NGF increased firing in noncholinergic neurons, and this effect was blocked by methyl scopolamine. We propose that these findings, in toto, indicate two cell type-specific mechanisms of NGF action in elevating the overall firing activity of cholinergic and noncholinergic neurons in the MS/DB: a TrkA signalingdependent mechanism in cholinergic neurons and a muscarinic receptor-mediated mechanism in noncholinergic neurons that is manifested through an elevated ambient level of acetylcholine.

\section{Is extracellular delivery of NGF directly into the MS/DB physiologically relevant?}

A prevailing concept marshaled by the neurotrophic hypothesis is that projecting axons internalize target-derived neurotrophin, which is then delivered by retrograde transport to the cell bodies whence the axons originate (for review, see Thoenen, 1995; Schinder and Poo, 2000). In the septohippocampal system, NGF fits into this conventional scheme insofar as it is synthesized in the hippocampus, with axons of projecting MS/DB neurons serving as conduit for retrograde transport to the MS/DB. Nonetheless, the scheme does not exclude other modes by which NGF may reach the MS/DB. Specifically, a number of studies have
B
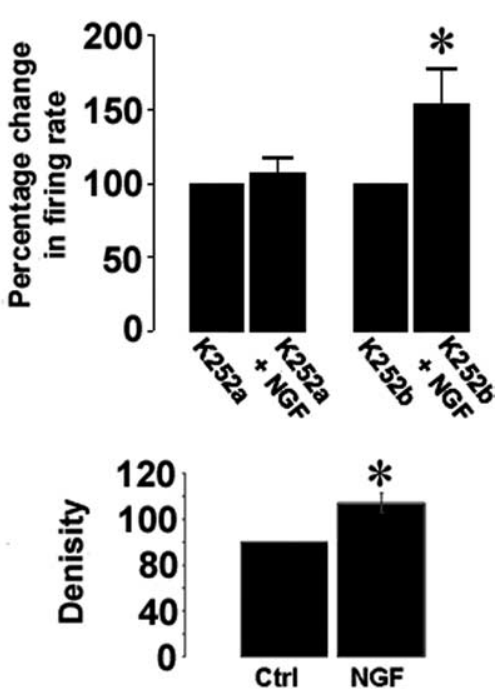

Figure 6. K252a inhibits NGF-induced increase in firing of cholinergic neurons. $A$, Rate-meter record from a cholinergic neuron illustrates that K252a ( $200 \mathrm{~nm}$ ) prevented the increase in firing normally observed during application of NGF (100 ng/ml), which, the same cell, persisted in the presence of K252b (200 nm). $\boldsymbol{B}$, Normalized histograms summarizing that K252a, but not K252b, . (he presence of $\mathrm{K} 252 \mathrm{~b}$ ( $p<0.05$; Student's $t$ test). C, Phosphorylated TrkA was detected in tissue obtained from MS/DB tissues. MS/DB tissues perfused with NGF displayed significantly stronger signal than that perfused with aCSF ( $p<0.05$; Student's $t$ test; $n=5$ ). Asterisks in $\boldsymbol{B}$ and $\boldsymbol{D}$ denote statistical significance. Ctrl, Control tissue processed in GF.

reported GABAergic interneurons and GABAergic hippocamposeptal neurons to be primary sites of NGF synthesis in the hippocampus (Lauterborn et al., 1993; Rocamora et al., 1996; Acsády et al., 2000). This suggests strongly that, in addition to retrograde transport, NGF can also be delivered anterogradely and be released extracellularly in the MS/DB. Furthermore, cholinergic MS/DB neurons express NGF mRNA (Lauterborn et al., 1991), pointing to the likelihood of yet another local intraseptal source of extracellular NGF.

The classical approach of lesioning the fimbria/fornix, widely used to investigate the septohippocampal system (Pepeu et al., 1973; Olton, 1977; Olton et al., 1978; Andersen et al., 1979), also offers insight into the physiological relevance and effectiveness of NGF action in the MS/DB. With fimbria/fornix lesioning, the hippocamposeptal retrograde transport is necessarily disrupted, yet numerous studies have demonstrated that intraventricular infusion of NGF has beneficial effects on cholinergic neurons, such as restoring ChAT expression and promoting cell survival (Hefti, 1986; Williams et al., 1986; Wilcox et al., 1995; LucidiPhillipi et al., 1996). In these studies, the exogenous NGF arguably reaches the MS/DB by diffusion rather than by retrograde transport. Indeed, delivery of NGF by infusion or by genetically engineered agents directly into the MS/DB also produced similar outcomes (Holtzman et al., 1992; Martinez-Serrano and Bjorklund, 1998; Mandel et al., 1999). The significance of different in vivo routes of NGF delivery to the MS/DB is unclear, although, in vitro, the particular signaling pathway activated appears to dictate whether or not retrograde transport of NGF occurs (Watson et al., 2001). Overall, extant literature supports the physiological relevance of investigating a direct and local effect of NGF in the MS/DB. 

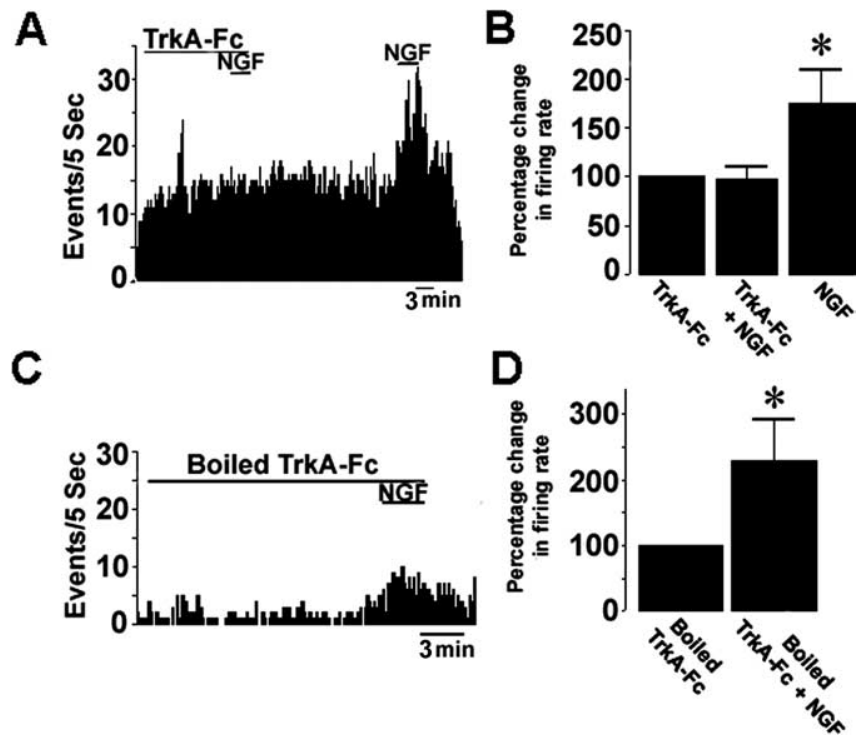

Figure 7. TrkA-Fc inhibits the acute effect of NGF on firing of cholinergic neurons. $A, C$, Representative rate-meter records of cholinergic neurons demonstrate spontaneous firing before, during, and after focal NGF ( $100 \mathrm{ng} / \mathrm{ml})$ application in the presence of TrkA-Fc and boiled TrkA-Fc, respectively. The cell in $A$ also showed increased firing in the presence of NGF only. $B, D$, Normalized histograms summarizing that TrkA-Fc, but not boiled TrkA-Fc, blocks the NGFinduced increase in mean firing rates of cholinergic neurons. In the presence of TrkA-Fc, the NGF-induced increase in mean firing rate of cholinergic neurons was not significantly different from that monitored during the TrkA-Fc only period ( $p>0.05 ; n=7$ ). The NGF effect resumed during washout of TrkA-Fc $(p<0.05)$. Boiled TrkA-Fc did not affect NGF-induced increase firing $(p<0.05 ;$ Student's $t$ test; $n=6$ ). Asterisks in $\boldsymbol{B}$ and $\boldsymbol{D}$ denote statistical significance.
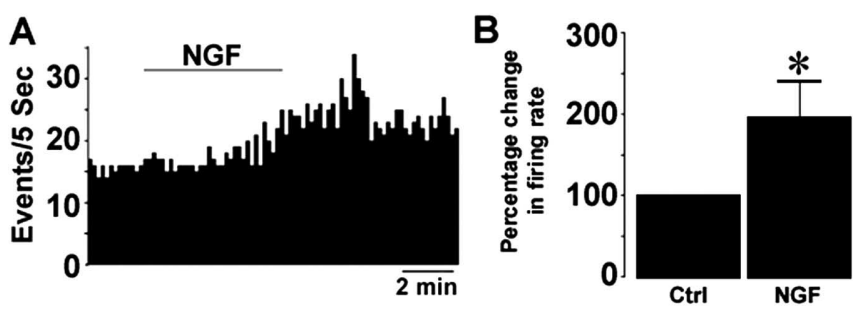

Figure 8. The NGF-induced effect on firing of cholinergic MS/DB neurons persists in p75 $5^{\mathrm{NTR}-1-}$ mice. $\boldsymbol{A}$, Representative rate-meter record of a cholinergic neuron from a p75 ${ }^{\mathrm{NTR}-1-}$ mouse demonstrates spontaneous firing before, during, and after focal NGF (100 $\mathrm{ng} / \mathrm{ml}$ ) application. $\boldsymbol{B}$, Summary histogram indicates that, under $\mathrm{p} 75^{\mathrm{NTR}-1-}$ conditions, NGF application significantly increased firing rate of MS/DB cholinergic neurons by $94 \pm 45 \%$ ( $n=$ $12 ;$ mean \pm SEM; $p<0.05$; Student's $t$ test). Asterisk denotes statistical significance. Ctrl, Control period before NGF application.

TrkA signaling pathway mediates acute NGF effect in MS/DB cholinergic neurons

In pheochromocytoma PC12 cells and primary neuronal cultures, TrkA has been demonstrated to promote survival and differentiation of neurons (Loeb et al., 1991; Loeb and Greene, 1993) (for review, see Davies, 2000; Kaplan and Miller, 2000). The results of the present study indicate that TrkA signaling is required for the observed rapid effect of NGF on the firing of cholinergic MS/DB neurons. In addition, immunohistochemical evidence was presented that, in the MS/DB, cholinergic but not GABAergic neurons express TrkA receptors. This provides the anatomical substrate that renders cholinergic neurons directly responsive to acute NGF application. Our pharmacological experiments provided additional supportive evidence. Blocking TrkA autophosphorylation with K252a prevented the NGFinduced increase firing in cholinergic neurons, as did sequester-
A

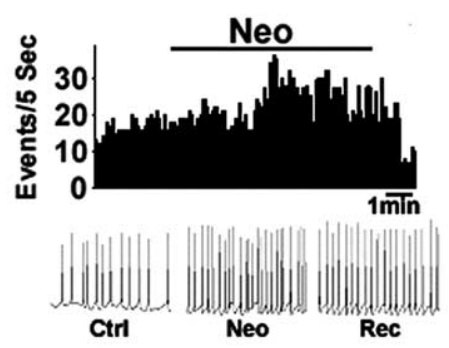

B

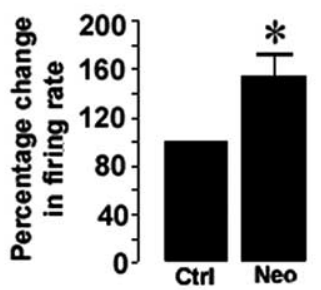

C
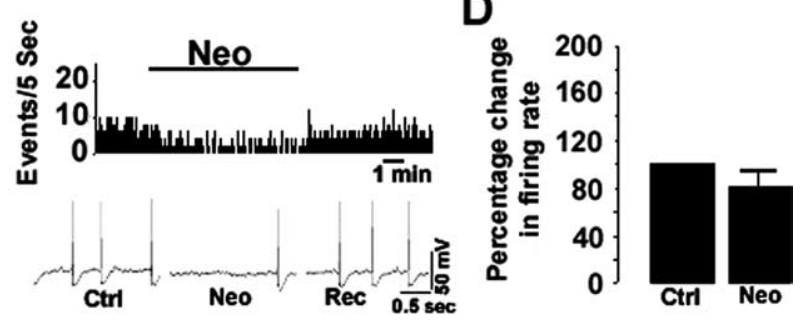

Figure 9. Neostigmine increases ambient acetylcholine in mouse MS/DB. A, C, Representative rate-meter records (top) and digitized traces (bottom) from a noncholinergic $(\boldsymbol{A})$ and cholinergic ( $C$ ) neuron, illustrating spontaneous firing rates before [control (Ctrl)], during, and after [recovery (Rec)] neostigmine (Neo) application. $\boldsymbol{B}, \boldsymbol{D}$, Normalized histograms summarizing mean spontaneous firing rates of noncholinergic $(\boldsymbol{B})$ and cholinergic $(\boldsymbol{D})$ neurons in the presence of neostigmine. The mean firing rate of noncholinergic neurons during exposure to neostigmine was significantly faster than that during the control period ( $n=16$; mean \pm SEM; $p<0.05$; Student's $t$ test), whereas that of cholinergic neurons was unaffected ( $n=15$; mean \pm SEM; $p>0.05$; Student's $t$ test). The asterisk in $\boldsymbol{B}$ denotes statistical significance.

A
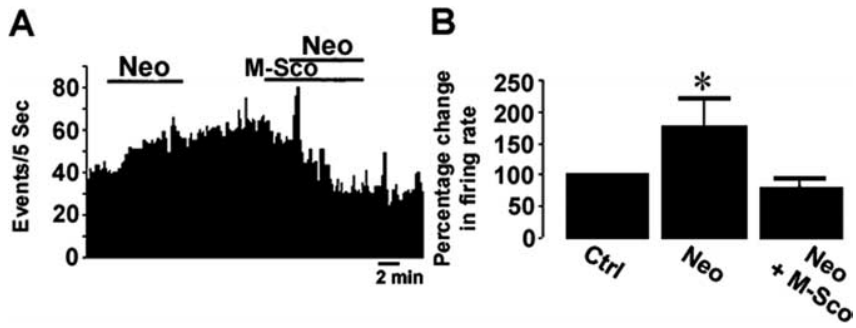

Figure 10. Methyl scopolamine blocks the neostigmine-induced increase in firing in noncholinergic neurons. $\boldsymbol{A}$, A representative rate-meter record displaying spontaneous firing of a noncholinergic neuron before [control (Ctrl)], during, and after neostigmine (Neo) application either alone or in conjunction with methyl scopolamine (M-Sco). $\boldsymbol{B}$, Histogram summarizing the normalized mean firing rate of noncholinergic neurons $(n=6)$ during neostigmine exposure without and with concomitant application of methyl scopolamine. With neostigmine alone, the mean firing rate of noncholinergic neurons was significantly faster $(78.2 \pm 45 \%$; mean \pm SEM; $p<0.05$; Student's $t$ test). The neostigmine-induced increase in firing was blocked in the presence of methyl scopolamine. The asterisk in $\boldsymbol{B}$ denotes statistical significance.

ing endogenous TrkA using TrkA-Fc, indicating further the specificity of NGF in this rapid effect.

Cholinergic MS/DB neurons uniquely express p75 ${ }^{\text {NTR }}$ (Berger-Sweeney et al., 2001). Although p75 ${ }^{\text {NTR }}$ displays a significantly lower affinity to NGF than do Trk receptors in general, a number of roles have been ascribed to it either acting alone or in synergy with TrkA. Acting alone, the $\mathrm{p} 75^{\mathrm{NTR}}$ has been implicated in playing a proapoptotic role (Casaccia-Bonnefil et al., 1996; Bamji et al., 1998). Acting in synergy, it has been reported to enhance Trk receptor autophosphorylation and signaling mechanisms downstream (for review, see Chao and Hempstead, 1999). Here we demonstrate that the increased firing in cholinergic neurons in response to NGF persists in MS/DB slices derived from p75 ${ }^{\mathrm{NTR}}$-null mice. Given our results, we favor the notion that p $75^{\text {NTR }}$ is not necessary or sufficient and that TrkA is predomi- 
nant in mediating the acute NGF effect observed on cholinergic MS/DB neurons. Nonetheless, our results do not rule out a potential synergistic interaction between p75 ${ }^{\text {NTR }}$ and TrkA receptors under normal conditions. Indeed, considering that p $75^{\text {NTR }}$-null mice display increased number of cholinergic neurons (Yeo et al., 1997; Naumann et al., 2002), an hypothesis to be entertained in future investigations is that this may result in heightened muscarinic tone in the MS/DB.

\section{Differential effects of NGF on}

cholinergic neurons and noncholinergic neurons in light of muscarinic tone in mouse MS/DB

In rat, the existence of intraseptal cholinergic collateral projections onto GABAergic neurons, born out of lesioning and ultrastructural studies (Onteniente et al., 1986, 1987; Bialowas and Frotscher, 1987; Leranth and Frotscher, 1989; Brauer et al., 1998), is consistent with the notion of a muscarinic tone in the MS/DB (Alreja et al., 2000). Although equivalent information in mouse is lacking, the pharmacological data presented in this study provide evidence for noncholinergic neurons being subject to a muscarinic tone in the mouse MS/DB. Application of neostigmine led to an increase in the firing of noncholinergic neurons, as did bath perfusion of slices with NGF-containing aCSF, and both effects were blocked by methyl scopolamine, the muscarinic receptor antagonist that, when applied alone, reversibly suppressed firing in noncholinergic neurons (data not shown). Neostigmine inhibits acetylcholinesterase and NGF augments firing activity of cholinergic MS/DB neurons; both agents would be expected to enhance extracellular availability of acetylcholine, a condition that simulates elevated muscarinic tone, and to increase firing of noncholinergic neurons, as was demonstrated in the present study. Overall, our findings are consistent with there being in mouse MS/DB an ambient level of acetylcholine, i.e., muscarinic tone, that tonically regulates the firing of noncholinergic neurons. In this light, firing activity of cholinergic neurons determines fluctuations in muscarinic tone in the MS/DB that, in turn, alters firing activity of noncholinergic neurons. Thus, despite the absence of TrkA expression, noncholinergic neurons, including GABAergic neurons, are subject to acute influence by NGF in the MS/DB.

\section{Functional significance}

Our findings lead us to conclude that acutely applied NGF triggers a rapid sequence of events that affects the cholinergic and noncholinergic neuronal populations in the MS/DB. NGF activates TrkA receptors expressed by cholinergic neurons, leading to increased cholinergic activity, elevated muscarinic tone, and a subsequent increase in the firing of noncholinergic neurons. Thus, muscarinic tone provides a functional index that reflects the net outcome of physiological interactions between cholinergic and noncholinergic neurons within the circuitry resident in the MS/DB and provides a functional framework for investigating long-term effects of NGF on neuronal activity in the septohippocampal system.

The rapid and reversible action of acutely applied NGF on the firing of neurons in the MS/DB is reminiscent of that of a neurotransmitter or neuromodulator and points to a novel role for the neurotrophin in addition to its well established neurotrophic function. As such, NGF may be classified functionally along with
B
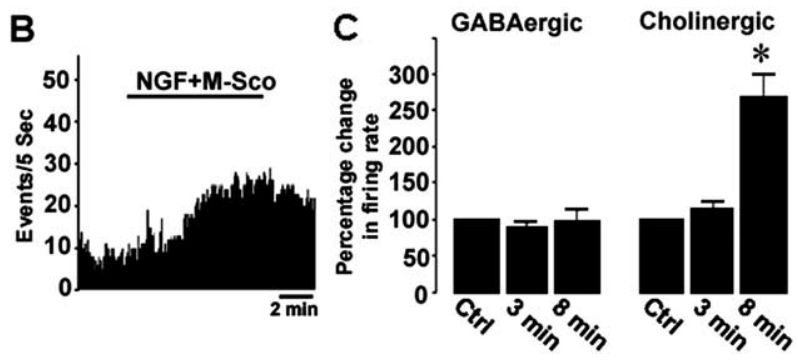

Figure 11. Methyl scopolamine blocks the increased firing in noncholinergic but not cholinergic neurons in response to bath perfusion of NGF. $\boldsymbol{A}, \boldsymbol{B}$, Representative rate-meter records of a noncholinergic and a cholinergic neuron, respectively, display spontaneous firing before (Ctrl, control), during, and after whole-slice NGF (100 ng/ml) perfusion in the presence of methy (M-Sco; $10 \mu \mathrm{M})$. C, Normalized histograms summarizing mean firing rates of noncholinergic, putatively GABAergic

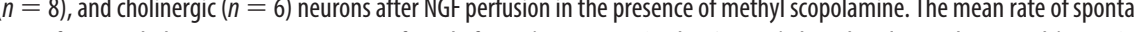
methyl scopolamine exposure) period, whereas that of noncholinergic neurons was abolished by methyl scopolamine $(p>0.05$;

brain-derived neurotrophic factor, a prototypic neurotrophin that has been widely demonstrated to modulate neuronal excitability, neurotransmission, and synaptic plasticity (Patterson et al., 1996; Stoop and Poo, 1996; Desai et al., 1999; Cheng and Yeh, $2003,2005)$. It is tempting to postulate that NGF derived from the hippocampus and retrogradely transported to the MS/DB may be important in mediating the longer-term trophic role of promoting cell survival and that local intraseptal release of NGF may, in the shorter term, lead to synaptic modulation within the circuitry resident in the MS/DB.

\section{References}

Acsády L, Pascual M, Rocamora N, Soriano E, Freund TF (2000) Nerve growth factor but not neurotrophin-3 is synthesized by hippocampal GABAergic neurons that project to the medial septum. Neuroscience 98:23-31.

Alreja M, Wu M, Liu W, Atkins JB, Leranth C, Shanabrough M (2000) Muscarinic tone sustains impulse flow in the septohippocampal GABA but not cholinergic pathway: implication for learning and memory. J Neurosci 20:8103-8110.

Andersen P, Bland HB, Myhrer T, Schwartzkroin PA (1979) Septohippocampal pathway necessary for dentate theta production. Brain Res 165:13-22.

Backman C, Rose GM, Hoffer BJ, Henry MA, Bartus RT, Friden P, Granholm AC (1996) Systemic administration of a nerve growth factor conjugate reverses age-related cognitive dysfunction and prevents cholinergic neuron atrophy. J Neurosci 16:5437-5442.

Bamji SX, Majdan M, Pozniak CD, Belliveau DJ, Aloyz R, Kohn J, Causing CG, Miller FD (1998) The p75 neurotrophin receptor mediates neuronal apoptosis and is essential for naturally occurring sympathetic neuron death. J Cell Biol 140:911-923.

Bender R, Plaschke M, Naumann T, Wahle P, Frotscher M (1996) Development of cholinergic and GABAergic neurons in the rat medial septum: different onset of choline acetyltransferase and glutamate decarboxylase mRNA expression. J Comp Neurol 372:204-214.

Berger-Sweeney J, Stearns NA, Murg SL, Floerke-Nashner LR, Lappi DA, Baxter MG (2001) Selective immunolesions of cholinergic neurons in mice: effects on neuroanatomy, neurochemistry, and behavior. J Neurosci 21:8164-8173.

Bialowas J, Frotscher M (1987) Choline acetyltransferase-immunoreactive neurons and terminals in the rat septal complex: a combined light and electron microscopic study. J Comp Neurol 259:298-307.

Blum R, Kafitz KW, Konnerth A (2002) Neurotrophin-evoked depolarization requires the sodium channel $\mathrm{Na}(\mathrm{V}) 1.9$. Nature 419:687-693.

Brauer K, Seeger G, Hartig W, Roßner S, Poethke R, Kacza J, Schliebs R, Bruckner G, Bigl V (1998) Electron microscopic evidence for a cholinergic innervation of GABAergic parvalbumin-immunoreactive neurons in the rat medial septum. J Neurosci Res 54:248-253.

Casaccia-Bonnefil P, Carter BD, Dobrowsky RT, Chao MV (1996) Death of 
oligodendrocytes mediated by the interaction of nerve growth factor with its receptor p75. Nature 383:716-719.

Celio MR (1990) Calbindin D-28k and parvalbumin in the rat nervous system. Neuroscience 35:375-475.

Chao MV, Hempstead BL (1999) p75 and Trk: a two-receptor system. Trends Neurosci 18:321-326.

Cheng Q, Yeh HH (2003) Brain-derived neurotrophic factor attenuates mouse cerebellar granule cell $\mathrm{GABA}_{\mathrm{A}}$ receptor-mediated responses via postsynaptic mechanisms. J Physiol (Lond) 538:711-721.

Cheng Q, Yeh HH (2005) PLC $\gamma$ signaling underlies BDNF potentiation of Purkinje cell responses to GABA. J Neurosci Res 79:616-627.

Chrobak JJ, Napier TC (1992) Antagonism of GABAergic transmission within the septum disrupts working/episodic memory in the rat. Neuroscience 47:833-841.

Clancy B, Darlington RB, Finlay BL (2001) Translating developmental time across mammalian species. Neuroscience 105:7-17.

Cobb SR, Buhl EH, Halasy K, Paulsen O, Somogyi P (1995) Synchronization of neuronal activity in hippocampus by individual GABAergic interneurons. Nature 378:75-78.

Davies AM (2000) More to NGF than just survival. Curr Biol 10:R374-R376.

Desai NS, Rutherford LC, Turrigiano GG (1999) BDNF regulates the intrinsic excitability of cortical neurons. Learn Mem 6:284-291.

Deutsch JA, Rocklin KW (1967) Amnesia induced by scopolamine and temporal variation. Nature 216:89-90.

DiStefano P, Friedman B, Radziejewski C, Alexander C, Boland P, Schick C, Lindsay R, Wiegand S (1992) The neurotrophins BDNF, NT-3 and NGF display distinct patterns of retrograde axonal transport in peripheral and central neurons. Neuron 8:983-993.

Dutar P, Bassant MH, Senut MC, Lamour Y (1995) The septohippocampal pathway: structure and function of a central cholinergic system. Physiol Rev 75:393-427.

Freund TF (1989) GABAergic septohippocampal neurons contain parvalbumin. Brain Res 78:375-381.

Freund TF, Antal M (1988) GABA-containing neurons in the septum control inhibitory interneurons in the hippocampus. Nature 336:170-173.

Gibbs RB, Martynowski C (1997) Nerve growth factor induces Fos-like immunoreactivity within identified cholinergic neurons in the adult rat basal forebrain. Brain Res 753:141-151.

Green JD, Arduini AA (1954) Hippocampal electrical activity in arousal. J Neurophysiol 17:533-557.

Griffith WH, Matthews RT (1986) Electrophysiology of AChE-positive neurons in basal forebrain slices. Neurosci Lett 71:169-174.

Gustilo MC, Markowska AL, Breckler SJ, Fleischman CA, Price DL, Koliatsos VE (1999) Evidence that nerve growth factor influences recent memory through structural changes in septohippocampal cholinergic neurons. J Comp Neurol 405:491-507.

Ha DH, Robertson RT, Roshanaei M, Weiss JH (1999) Enhanced survival and morphological features of basal forebrain cholinergic neurons in vitro: role of neurotrophins and other potential cortically derived cholinergic trophic factors. J Comp Neurol 406:156-170.

Han SH, McCool BA, Murchison D, Nahm SS, Parrish AR, Griffith WH (2002) Single-cell RT-PCR detects shifts in mRNA expression profiles of basal forebrain neurons during aging. Brain Res Mol Brain Res 98:67-80.

Hefti F (1986) Nerve growth factor promotes survival of septal cholinergic neurons after fimbrial transections. J Neurosci 6:2155-2162.

Holtzman DM, Li Y, Parada LF, Kinsman S, Chen C-K, Valletta JS, Zhou J, Long JB, Mobley WC (1992) p140trk mRNA marks NGF-responsive forebrain neurons: evidence that trk gene expression is induced by NGF. Neuron 9:465-478.

Huang EJ, Reichardt LF (2001) Neurotrophins: roles in neuronal development and function. Annu Rev Neurosci 24:677-736.

Jones GA, Norris SK, Herderson Z (1999) Conduction velocities and membrane properties of different classes of rat septohippocampal neurons recorded in vitro. J Physiol (Lond) 517:867-877.

Kafitz KW, Rose CR, Thoenen H, Konnerth A (1999) Neurotrophin-evoked rapid excitation through TrkB receptors. Nature 401:918-921.

Kaplan DR, Miller FD (2000) Neurotrophin signal transduction in the nervous system. Curr Opin Neurol 10:381-391.

Kiss J, Patel AJ, Freund TF (1990) Distribution of septohippocampal neurons containing parvalbumin or choline acetyltransferase in the rat brain. J Comp Neurol 258:362-372.
Lapchak PA, Araujo DM, Carswell S, Hefti F (1993) Distribution of [ $\left.{ }^{125} \mathrm{I}\right] \mathrm{n}$ erve growth factor in the rat brain following a single intraventricular injection: correlation with the topographical distribution of trkA messenger RNA-expressing cells. Neuroscience 54:445-460.

Lauterborn JC, Isackson PJ, Gall CM (1991) Nerve growth factor mRNAcontaining cells are distributed within regions of cholinergic neurons in the rat basal forebrain. J Comp Neurol 306:439-446.

Lauterborn JC, Tran TM, Isackson PJ, Gall CM (1993) Nerve growth factor mRNA is expressed by GABAergic neurons in rat hippocampus. NeuroReport 5:273-276.

Lee KF, Li E, Huber LJ, Landis SC, Sharpe AH, Chao MV, Jaenisch R (1992) Targeted mutation of the gene encoding the low affinity NGF receptor p75 leads to deficits in the peripheral sensory nervous system. Cell 69:737-749.

Leranth C, Frotscher M (1989) Organization of the septal region in the rat brain: cholinergic-GABAergic interconnections and the termination of hippocampo-septal fibers. J Comp Neurol 289:304-314.

Linke R, Frotscher M (1993) Development of the rat septohippocampal projection: tracing with DiI and electron microscopy of identified growth cones. J Comp Neurol 332:69-88.

Linke R, Pabst T, Frotscher M (1995) Development of the hippocamposeptal projection in the rat. J Comp Neurol 351:602-616.

Loeb DM, Greene LA (1993) Transfection with trk restores "slow" NGF binding, efficient NGF uptake, and multiple NGF responses to NGFnonresponsive PC12 cell mutants. J Neurosci 13:2919-2929.

Loeb DM, Maragos J, Martin-Zanca D, Chao MV, Parada LF, Greene LA (1991) The trk proto-oncogene rescues NGF responsiveness in mutant NGF-nonresponsive PC12 cell lines. Cell 66:961-966.

Lucidi-Phillipi CA, Clary DO, Reichardt LF, Gage FH (1996) TrkA activation is sufficient to rescue axotomized cholinergic neurons. Neuron 16:653-663.

Mandel RJ, Gage FH, Clevenger DG, Spratt SK, Snyder RO, Leff SE (1999) Nerve growth factor expressed in the medial septum following in vivo gene delivery using a recombinant adeno-associated viral vector protects cholinergic neurons from fimbria-fornix lesion-induced degeneration. Exp Neurol 155:59-64.

Markram H, Segal M (1990) Electrophysiological characteristics of cholinergic and non-cholinergic neurons in the rat medial septum-diagonal band complex. Brain Res 513:171-174.

Martinez-Serrano A, Bjorklund A (1998) Ex vivo nerve growth factor gene transfer to the basal forebrain in presymptomatic middle-aged rats prevents the development of cholinergic neuron atrophy and cognitive impairment during aging. Proc Natl Acad Sci USA 95:1858-1863.

Milner TA, Loy R, Amaral DG (1983) An anatomical study of the development of the septo-hippocampal projection in the rat. Dev Brain Res 8:343-371.

Mobley WC, Rutkowski JL, Tennekoon GI, Gemski J, Buchanan K, Johnston MV (1986) Nerve growth factor increases choline acetyltransferase activity in developing basal forebrain neurons. Brain Res 387:53-62.

Naumann T, Casademunt E, Hollerbach E, Hofmann J, Dechant G, Frotscher M, Barde Y-A (2002) Complete deletion of the neurotrophin receptor p $75^{\text {NTR }}$ leads to long-lasting increases in the number of basal forebrain cholinergic neurons. J Neurosci 22:2409-2418.

Olton DS (1977) The function of septo-hippocampal connections in spatially organized behaviour. Ciba Found Symp 58:327-349.

Olton DS, Walker JA, Gage FH (1978) Hippocampal connections and spatial discrimination. Brain Res 139:295-308.

Onteniente B, Tago H, Kimura H, Maeda T (1986) Distribution of $\gamma$-aminobutyric acid-immunoreactive neurons in the septal region of the rat brain. J Comp Neurol 248:422-430.

Onteniente B, Geffard M, Campistron G, Calas A (1987) An ultrastructural study of GABA-immunoreactive neurons and terminals in the septum of the rat. J Neurosci 7:48-54.

Palacios G, Garcia-Ladona J, Codine M (1991) Ultrastructural study of cholinergic neurons in the medial septal nucleus and vertical limb of the diagonal band of Broca in the basal forebrain of the rat. J Comp Neuroanat 4:205-221.

Panula P, Revuelta AV, Cheney DL, Wu JY, Costa E (1984) An immunohistochemical study on the location of GABAergic neurons in rat septum. J Comp Neurol 222:69-80.

Patterson SL, Abel T, Deuel TA, Martin KC, Rose JC, Kandel ER (1996) Recombinant BDNF rescues deficits in basal synaptic transmission and hippocampal LTP in BDNF knockout mice. Neuron 16:1137-1145. 
Pepeu G, Mulas A, Mulas ML (1973) Changes in the acetylcholine content in the rat brain after lesions of the septum, fimbria and hippocampus. Brain Res 57:153-164.

Poucet B, Herrmann T (1990) Septum and medial frontal cortex contribution to spatial problem-solving. Behav Brain Res 37:269-280.

Rocamora N, Pascual M, Acsady L, de Lecea L, Freund TF, Soriano E (1996) Expression of NGF and NT3 mRNAs in hippocampal interneurons innervated by the GABAergic septohippocampal pathway. J Neurosci 16:3991-4004.

Schinder AF, Poo M (2000) The neurotrophin hypothesis for synaptic plasticity. Trends Neurosci 23:639-645.

Seiler M, Schwab ME (1984) Specific retrograde transport of nerve growth factor (NGF) from neocortex to nucleus basalis in the rat. Brain Res 300:33-39.

Sotty F, Danik M, Manseau F, Laplante F, Quirion R, Williams S (2003) Glutamatergic, cholinergic and GABAergic neurons contribute to the septohippocampal pathways and exhibit distinct electrophysiological properties: novel implications for hippocampal rhythmicity. J Physiol (Lond) 551:927-943.

Stoop R, Poo MM (1996) Synaptic modulation by neurotrophic factors: differential and synergistic effects of brain-derived neurotrophic factor and ciliary neurotrophic factor. J Neurosci 16:3256-3264.

Thoenen H (1995) Neurotrophins and neuronal plasticity. Science 270:593-598.

Tøth K, Borhegyi Z, Freund TF (1993) Postsynaptic targets of GABAergic hippocampal neurons in the medial septum-diagonal band of Broca complex. J Neurosci 13:3712-3724.

Tøth K, Freund TF, Miles R (1997) Disinhibition of rat hippocampal pyramidal cells by GABAergic afferents from the septum. J Physiol (Lond) 500:463-474.

Vanderwolf CH (1969) Hippocampal electrical activity and voluntary movement in the rat. Electroencephalogr Clin Neurophysiol 26:407-418.
Van der Zee EA, Luiten PGM (1994) Cholinergic and GABAergic neurons in the rat medial septum express muscarinic acetylcholine receptors. Brain Res 652:263-272.

Ward NL, Hagg T (1999) p75 (NGFR) and cholinergic neurons in the developing forebrain: a re-examination. Brain Res Dev Brain Res 118:79-91.

Ward NL, Hagg T (2000) BDNF in needed for postnatal maturation of basal forebrain and neostriatum cholinergic neurons. Exp Neurol 162:297-310.

Watson FL, Heerssen HM, Bhattacharyya A, Klesse L, Lin MZ, Segal RA (2001) Neurotrophins use the Erk5 pathway to mediate a retrograde survival response. Nat Neurosci 4:981-988.

Whitehouse PJ, Price DL, Struble RG, Clark AW, Coyle JT, Delon MR (1982) Alzheimer's disease and senile dementia: loss of neurons in the basal forebrain. Science 215:1237-1239.

Wilcox BJ, Applegate MD, Portera-Cailliau C, Koliatsos VE (1995) Nerve growth factor prevents apoptotic cell death in injured central cholinergic neurons. J Comp Neurol 359:573-585.

Williams LR, Varon S, Peterson GM, Wictorin K, Fischer W, Bjorklund A, Gage FH (1986) Continuous infusion of nerve growth factor prevents basal forebrain neuronal death after fimbria fornix transection. Proc Natl Acad Sci USA 83:9231-9235.

Winson J (1974) Patterns of hippocampal theta rhythm in the freely moving rat. Electroencephalogr Clin Neurophysiol 36:291-301.

Wu M, Shanabrough M, Leranth C, Alreja M (2000) Cholinergic excitation of septohippocampal GABA but not cholinergic neurons: implications for learning and memory. J Neurosci 20:3900-3908.

Yeo TT, Chua-Couzens J, Butcher LL, Bredesen DE, Cooper JD, Valletta JS, Mobley WC, Longo FM (1997) Absence of p75 ${ }^{\text {NTR }}$ causes increased basal forebrain cholinergic neuron size, choline acetyltransferase activity, and target innervation. J Neurosci 17:7594-7605. 